\title{
A review on the relationship between marital adjustment and maternal attachment
}

\author{
Birsen Mutlu ${ }^{1}$, Zeynep ErkuT2* ${ }^{2 *}$, Zeynem Yildirim³${ }^{3}$, Nurgül GündoĞdu ${ }^{4}$ \\ ${ }^{1}$ Assistant Professor at Istanbul University Florence Nightingale Faculty of Nursing, Istanbul, Turkey \\ ${ }^{2}$ Research Assistant at Istanbul University Florence Nightingale Faculty of Nursing, Istanbul, Turkey \\ ${ }^{3}$ Lecturer at Namık Kemal University Health School Pediatric Nursing Department, Tekirdag, Turkey \\ ${ }^{4}$ Bağcilar Education and Research Hospital, Istanbul, Turkey
}

Study conducted at the Bağcılar Training and Research Hospital Pediatrics Clinic, Istanbul, Turkey

Article received: $10 / 1 / 2017$ Accepted for publication: 11/2/2017

*Correspondence: Address: Abide-i Hürriyet Street Şişli Istanbul - Turkey

Postal code: 34381 zeeyynneepp05@hotmail.com

\section{SUMMARY}

Objective: To determine the relationship between marital adjustment of mothers who have babies between 1-4 months old and their maternal attachment; as well as the relationship of maternal attachment and marital adjustment with sociodemographic characteristics.

Method: The research is descriptive and correlational. Its sample consists of 113 mothers. Maternal Attachment Index (MAI) and Marital Adjustment Scale (MAS) are used as data collection tools.

Results: We found that, for mothers who participated in this research, the average level of maternal attachment is $92.17 \pm 8.49$, and the average level of marital adjustment is $43.06 \pm 7.90$. We discovered that the maternal attachment level is higher for mothers who have completed high school and university, those who breastfeed their babies exclusively and whose spouses help care for the baby. We also discovered that the Marital Adjustment Score is higher among mothers who are employed, get married by companionship (not arranged), continue attending pregnancy classes and whose duration of marriage is between $1-5$ years and $10-15$ years. There is weak positive relationship $(\mathrm{r}=0.38 ; \mathrm{p}=0.00)$ between marital adjustment and maternal attachment; and the regression analysis that is run to explain this relationship is statistically significant $(F=26.131 ; \mathrm{p}<0.05)$.

Conclusion: In our study, the level of maternal attachment was high, while the level of marital adjustment was liminal. There are many factors affecting sociodemographic characteristics, pregnancy and baby care. The level of marital adjustment for mothers increases the maternal attachment.

Keywords: Mothers. Mother-child Relations. Family Relations. Marriage.

\section{INTRODUCTION}

Family is the smallest building block of the society and good family relations is the guarantee of the future of the society. ${ }^{1}$ The foundation of the family is laid through the marriage of couples who pledges many promises to each other, such as commitment, faithfulness and fulfilling responsibilities. ${ }^{2,3}$ After marriage, individuals start to live together and raise their children that will be born in their family environment. ${ }^{4,5}$ The quality of the marriage is determined with concepts of adjustment, satisfaction and happiness, as well as evaluations of married couples. ${ }^{1}$ Marital adjustment is the satisfaction and happiness couples have in their marriage. ${ }^{6}$ There are many factors affecting the marital adjustment of couples, such as ages of couples, duration of marriage, communication between them, fulfilling their desires and expectations, making common decisions, relations with the family and relatives, agreeing on leisure time activities and family budget. ${ }^{1}$ The interaction of children who are raised in a family environment with marital adjustment, consistency and stability is more qualified and they have healthier adolescence. ${ }^{7}$ According to the social learning theory of Bandura, a child learns negative behavior examples through observation. ${ }^{8}$ Problems brought by marital maladjustment may cause couples to demonstrate negative behaviors which lead to the formation of problematic behaviors in 
children and make them take negative behaviors as their role model. ${ }^{79}$

The word "attachment" is used for both "the attachment of the baby to mother" and "the emotional bonding between mother and children." ${ }^{\prime 10}$ Maternal attachment is a unique relationship that develops between the mother and the baby, is persistent, ${ }^{11,12}$ carries on its impact for lifetime by affecting the development, relationship and adjustment of the child. ${ }^{10}$ Existence of a warm, persistent and close relationship between the mother and the baby, ${ }^{13}$ and formation of satisfactory interaction and attachment ${ }^{14}$ positively affect the development of maternal attachment. This is the basis of the attachment experiences that the child will have later. If there is no reliable attachment established in the first year of the life, the baby might have emotional, social, physical, mental and lingual development problems. ${ }^{12}$ Midwives/nurses have critical roles in stimulating positive mother-infant relationship after delivery, supporting and evaluating the normal attachment process between mother and infant.

The purpose of this research was to determine the relationship between marital adjustment of mothers who have babies between 1-4 months old and their maternal attachment; as well as the relationship of maternal attachment and marital adjustment with sociodemographic characteristics. The research attempts to provide answers for questions of "Is there a relationship between marital adjustment and maternal attachment?" and "Is there a relationship between marital adjustment, maternal attachment and sociodemographic characteristics of parents?"

\section{Method}

This is a descriptive and correlational study, conducted in the Bağcllar Training and Research Hospital Pediatrics Clinic between December 2014 and April 2015, with the participation of mothers that had babies between 1-4 months old. Before starting the research, the approval of the institution and the Bağcllar Training and Research Hospital Ethics Committee approval (decision no:2015353) was obtained.

It was calculated that at least 109 people were needed for the research in order to have $90 \%$ significance with $\alpha=0.05$ level, when the correlation between Marital Adjustment Score and Maternal Attachment Score was projected to have mid-level (r:0.300) influence. The sample consisted of 113 mothers who had 1-4 months old babies receiving treatment in pediatric clinics during the period of the research.

\section{Data collection tools}

Information form, Maternal Attachment Index and Marital Adjustment Scale (MAS) were used as data collection tools.

\section{Information form}

It involved 19 questions that were prepared by researchers pondering information about sociodemographic characteristics, marriage, pregnancy, maternity and baby.

\section{Maternal Attachment Index}

Maternal Attachment Index (MAI) was developed by Mary E. Muller in 1994 to measure attachment with maternal love. Muller has formed the questions of the index through the literature examining maternal adaptation and maternal attachment. MAI, which measures maternal emotions and behaviors demonstrating love, is an index that illiterate women can apply by themselves. ${ }^{11}$ Studies on validity and reliability tests for the Turkish version of the MAI were completed by Kavlak and Sirin in 2004 with the participation of 165 mothers who have healthy babies. ${ }^{12}$ This index includes 26 articles with 4-point Likert scale varying between "always" and "never." Each article has direct statements and is calculated as "Always $(\mathrm{a})=4$ points, Often $(\mathrm{b})=3$ points, Sometimes $(c)=2$ points and Never $(d)=1$ point." The lowest score to be obtained from the index is 26 and the highest score is 104 . The increase in the overall score obtained from the scale shows that mother's maternal attachment increases. ${ }^{12}$

\section{Marital Adjustment Scale (MAS)}

The scale has 15 articles in total and was developed by Locke and Wallace. ${ }^{15}$ The validity and reliability tests for the Turkish version of the scale were completed by KışlakTutarel. ${ }^{16}$ In MAS, one question measures general adjustment, eight questions measure possible agreement spaces, and six questions measure the adjustment regarding conflict resolution, loyalty and communication. Scores to be obtained from the scale range between 1 and 60 and higher scores show marital adjustment, whereas lower scores show marital maladjustment. The breakpoint to differentiate individuals with adjusted and maladjusted marriages is determined to be $43.5 .{ }^{16}$

For mothers who agreed to participate in the research after being informed, a consent form was signed. The mothers were then informed about how to fill in the MAI and MAS. They were asked to fill them completely. 


\section{Evaluation of the data}

Frequencies, percentages, means and standard deviations were used to analyze the data. Mann-Whitney $\mathrm{U}$ test and Kruskall Wallis test were used to compare the data. The correlation between variables was identified with Spearman Correlation and Regression Analysis. The statistical significance was defined to be $\mathrm{p}<0.05$. In addition to the researchers, a statistics expert was also involved in the data analysis process.

\section{Results}

According to characteristics of the research group, we found that most of them were part of a nuclear family (80.5\%), had one or two children (34.5\%), were aged between $26-30$ years $(34.5 \%)$, had primary or secondary school degrees (34.5\%) and were not working (85.8\%). The age of getting married for $47.8 \%$ of mothers was $21-25$ years old, the duration of marriage for $55.8 \%$ of them was $1-5$ years and $56.6 \%$ of them got married by companionship (not arranged). $96.5 \%$ of them became pregnant in a natural way, and it was intentional in $81.4 \%$ of the cases; $57.5 \%$ of the babies were boys and $51.3 \%$ of them were breastfed exclusively (Table 1).

The average of the level of maternal attachment for mothers who participated in the research was $92.17 \pm 8.49$. Considering that the lowest score that can be obtained from the MAI is 26 and the highest score is 104, the maternal attachment level for mothers was high. The average of the level of marital adjustment for the research group ranges between $43.06 \pm 7.90$. Considering that the breakpoint is 43.5 to differentiate between well-adjusted and maladjusted in the MAS, the marital adjustment for the research group was considered marginal (Table 2).

Table 3 presents comparison of maternal attachment and marital adjustment scores for mothers with descriptive characteristics of the group. We found a statistically significant $(\mathrm{p}<0.05)$ difference between average maternal attachment scores of mothers that participated in the research and their level of education; and maternal attachment scores of mothers who were high school or university graduates is higher than those who are only literate $(p=0.03)$. A statistically significant difference was observed between the two types of marriage in terms of the participants' maternal attachment scores. The mean maternal attachment score was higher for those who got married by companionship in comparison to those participants who entered arranged marriages $(p=0.00)$. We found a statistically significant relationship between maternal attachment and type of feeding for the baby; and the average of maternal attachment scores was higher for mothers who breastfeed exclusively compared to those breastfeeding as well as offering baby formula $(\mathrm{p}=0.00)$ (Figure 1). It was established that the average of maternal attachment scores for mothers whose spouses help caring for the baby care was statistically significant higher $(\mathrm{p}=0.02)$ (Figure 2$)$. There was no statistically significant difference between maternal attachment and age of mother, employment status for mother, family type, number of children in the family, age at the time of marriage, duration of marriage and gender of the baby ( $p>0.05)$.

When descriptive characteristics of the group and average of their marital adjustment scores were compared, it was found that the marital adjustment scores were higher for working mothers compared to those who were not working $(\mathrm{p}=0.04)$, for those who got married by companionship compared to those with arranged marriages $(\mathrm{p}=0.01)$, for those whose duration of marriage was 1-5 years and 10-15 years compared to those whose duration of marriage was 6-10 years. There was a statistically significant difference between average of marital adjustment scores of mothers and their level of education; marital adjustment scores of mothers who were graduates of high school and university were higher than for those who were only literates and illiterates $(\mathrm{p}=0.00)$; additionally, marital adjustment scores for mothers who were university graduates were higher compared to those who were graduates of primary and secondary schools $(\mathrm{p}=0.00)$. In case of having spouses providing support for baby care, the average of marital adjustment scores was statistically significantly higher $(\mathrm{p}=0.001)$ (Figure 2$)$. There was no statistically significant difference between marital adjustment and age of mother, family type, number of children in family, age of getting married, gender of baby and type of feeding for the baby ( $p>0.05$ ).

Table 4 presents the comparison of maternal attachment and marital adjustment scores for mothers according to their pregnancy, natal and postnatal characteristics. The average of maternal attachment scores was statistically significantly higher for mothers who went to regular checks during their pregnancy compared to those who did not $(\mathrm{p}=0.00)$. There was no statistically significant difference between the average of maternal attachment scores and type of conception, actualization of pregnancy, experiencing problems during pregnancy, attending pregnancy classes, delivery method, experiencing problems during delivery and baby staying in the hospital after birth ( $p>0.05)$.

When the average of marital adjustment scores for mothers that participated in the research was examined, the average of marital adjustment scores was statistically significantly higher for those who became pregnant in a 
natural way, got regular checks during pregnancy and attended pregnancy classes $(\mathrm{p}<0.05)$. There was no statistically significant difference between the average of marital adjustment scores and type of conception, experiencing problems during pregnancy, type of delivery, experiencing problems during delivery and baby staying at the hospital after birth ( $>0.05)$.

Table 5 presents the correlation between level of maternal attachment and marital adjustment levels for mothers. There was a weak and positive correlation between marital adjustment and maternal attachment $(\mathrm{r}=0.38 ; \mathrm{p}=0.00)$.

The regression analysis, which was run to identify the correlation between marital adjustment and maternal attachment, was statistically significant $(\mathrm{F}=26,131$; $\mathrm{p}<0.05)$. The correlation between the variables maternal attachment and marital adjustment, which was a determinant of maternal attachment level (explanatory power), was weak $\left(\mathrm{R}^{2}=0.183\right)$. The level of marital adjustment for mothers increased their level of maternal attachment ( $(=0.469)$ (Table 6) (Figure 3). According to these results, marital adjustment was a determinant of maternal adjustment. Its weight on maternal attachment was $18.3 \%$.

\section{Discussion}

In this study, which was conducted to determine the relationship between marital adjustment of mothers who had babies between 1-4 months old and their maternal attachment, the level of maternal attachment for mothers was high (92.17 \pm 8.49$)$; and their level of marital adjustment was liminal (43.06 \pm 7.90$)$ (Table 2$)$. In a study conducted by Alan and Ege ${ }^{17}$ with 135 mothers that had 4-6 months old babies, the average MAI was $96.53 \pm 9.25$. In the research conducted by Kavlak and Şirin ${ }^{12}$ on the adaptation of MAI for Turkish society, the average score of maternal attachment for mothers with 1-month old babies was found to be $94.87 \pm 6.04$, and for mothers with 4-months old babies, $95.85 \pm 6.29$. In a study conducted by Öztürk and Saruhan ${ }^{18}$ on the relationship between depression and maternal attachment for mothers who had 1-4 month old premature babies treated in hospital, the average of maternal attachment scores was $87.18 \pm$ 5.46. Shin and $\mathrm{Kim}^{19}$ found, in a study with 196 Korean mothers, an average score of maternal attachment of 94.26 \pm 9.74 . While the average score of maternal attachment in the present study shows parallelism with findings of other studies about babies with similar age groups, it was relatively higher than scores of studies on mothers whose premature babies are treated in the hospital. ${ }^{18}$ The find- ings of these studies demonstrate that the maternal attachment scores increase as babies grow up. Moreover, mothers are able to stay with their babies during their treatment period in hospital and the attachment process is not affected. It is thought that this information supports the high levels of maternal attachment.

We observed a statistically significant difference $(p<0.05)$ between maternal attachment scores and their level of education; the maternal attachment scores for mothers who were graduates of high school or university was higher than those who were only literates (Table 3). In the research conducted by Alan and Ege, ${ }^{17}$ there was no statistically significant relationship between the average MAI scores for mothers and their level of education. Also, in another research, it was demonstrated that there was no relationship between the level of education of the mother and attachment. ${ }^{20}$

Breastfeeding increases safe attachment by enabling mother to develop deep and lasting bond with her child and meet the child's needs with care and kindliness. ${ }^{10}$ When the maternal attachment scores and type of feeding for the baby were compared, there was a statistically significant difference $(\mathrm{p}<0.05)$; the scores of mothers who breastfeed exclusively were higher than those who combined breastfeeding and baby formula (Table 3). In the study conducted by Himani and $\mathrm{Kumar}^{21}$ examining the attachment between mothers and babies, breastfeeding within the first hour of birth increased the mother-baby attachment. In another research, the authors found that attachment problems increased with mothers who were not able to provide breast milk or provided additional baby formula for any reason..$^{22}$

In order for parents to have marital adjustment, factors such as family type, type of marriage and duration of their marriage are influential. ${ }^{7}$ In the research conducted by Ende İnce and Güdücü Tüfekçi ${ }^{23}$ to evaluate marital adjustment and life satisfaction of parents with disabled children and to identify influential factors, marital adjustment was higher for parents who got married by companionship. We observed that the marital adjustment scores for those with compassionate marriage were higher than those with arranged marriages $(\mathrm{p}<0.05)$ (Table 3 ). In light of these findings, it can be commented that companionship of couples when getting married and taking responsibilities in it increases marital adjustment.

We found that there was a statistically significant difference $(\mathrm{p}<0.05)$ between duration of marriage and marital adjustment scores; the marital adjustment scores for those whose duration of marriage was $1-5$ years and 10-15 years were higher than those whose duration of 
TABLE 1 Distribution of mothers according to their descriptive characteristics $(N=113)$.

\section{Characteristics}

Family type

No. of children in the family

Employment status for mother

Age at the time of marriage

Type of conception

Planning of pregnancy

Delivery method

Gender of the baby

Type of feeding for the baby
Nuclear family

Extended family

1

4 and more

16-20

21-25

26-30

31-35

Above 35

Illiterate

Literate

Primary and elementary school

High school

University

Working

Not working

15-20

$21-25$

Above 25

$1-5$ years

6-10 years

$11-15$ years

More than 15 years

Companionate marriage (not arranged)

Arranged marriage (traditional marriage)

Normal

Assisted reproductive techniques

Planned

Unplanned

Normal

C-section

Girl

Boy

Breastfeeding exclusively

Breastfeeding and baby formula

Breast milk by breast milking and baby formula

91

$\%$

80.5

19.5

38.9

39

34.5

15

13

11.5

9.7

30.1

34.5

15

13.3

12.4

17.7

19.5

34.5

39

22

19.5

8.8

16

14.2

97

85.8

48

54

11

11

63

31

13

6

64

49

109

42.5

47.8

9.7

55.8

27.4

11.5

5.3

56.6

43.4

96.5

$4 \quad 3.5$

92

81.4

21

18.6

59

52.2

54

47.8

48

48

42.5

65

57.5

58

44

51.3

38.9

11
9.7 
TABLE 2 Level of maternal attachment and marital adjustment for mothers.

\begin{tabular}{lllll} 
& Mean \pm SD & Min. & Max. & Scale Min-Max. \\
\hline Maternal attachment score & $92.17 \pm 8.49$ & 63.00 & 104.00 & $26-104$ \\
\hline Marital adjustment score & $43.06 \pm 7.90$ & 21.00 & 58.00 & $0-60$
\end{tabular}

TABLE 3 Comparison of maternal attachment and marital adjustment scores for mothers with descriptive characteristics of

the group.

Descriptive characteristics

Maternal Attachment Score Marital Adjustment Score

\begin{tabular}{|c|c|c|c|c|c|c|c|}
\hline & $N=113$ & Mean $\pm S D$ & Test value & p-value & Mean $\pm S D$ & Test value & p-value \\
\hline \multicolumn{8}{|l|}{ Age of mother } \\
\hline $16-20$ & 11 & $91.18 \pm 11.67$ & \multirow[t]{5}{*}{$3.21^{*}$} & \multirow[t]{5}{*}{0.52} & $41.90 \pm 8.96$ & \multirow[t]{5}{*}{$7.31 *$} & \multirow[t]{5}{*}{0.12} \\
\hline $21-25$ & 34 & $92.94 \pm 7.95$ & & & $45.23 \pm 7.69$ & & \\
\hline $26-30$ & 39 & $91.56 \pm 7.53$ & & & $41.48 \pm 7.35$ & & \\
\hline $31-35$ & 15 & $94.80 \pm 8.21$ & & & $45.13 \pm 7.08$ & & \\
\hline$>35$ & 14 & $90 \pm 10$ & & & $40.85 \pm 9.15$ & & \\
\hline \multicolumn{8}{|l|}{ Employment status for mother } \\
\hline Working & 16 & $93.93 \pm 7.99$ & \multirow{2}{*}{$655^{* *}$} & \multirow{2}{*}{0.31} & $46.31 \pm 8.22$ & \multirow{2}{*}{$532 * *$} & \multirow[t]{2}{*}{0.04} \\
\hline Not working & 94 & $91.88 \pm 8.57$ & & & $42.52 \pm 7.76$ & & \\
\hline \multicolumn{8}{|l|}{ Level of education for mother } \\
\hline Literate $^{2}$ & 22 & $89.13 \pm 7.89$ & \multirow{4}{*}{$10.18^{*}$} & Diff. & $40.27 \pm 7.2$ & \multirow{4}{*}{$13.48^{*}$} & $5>1,2,3$ \\
\hline Primary and elementary school graduate ${ }^{3}$ & 39 & $92.79 \pm 8.24$ & & $4>2$ & $44.00 \pm 5.96$ & & \multirow[t]{3}{*}{$4>1,2$} \\
\hline High school graduate ${ }^{4}$ & 22 & $94.40 \pm 8.83$ & & $5>2$ & $45.54 \pm 7.15$ & & \\
\hline University graduate ${ }^{5}$ & 10 & $96.10 \pm 5.80$ & & & $49.20 \pm 8.20$ & & \\
\hline \multicolumn{8}{|l|}{ Family type } \\
\hline Nuclear family & 91 & $92.16 \pm 8.56$ & \multirow[t]{2}{*}{$994.5^{* *}$} & \multirow[t]{2}{*}{0.96} & $43.70 \pm 7.90$ & \multirow[t]{2}{*}{$744 * *$} & \multirow[t]{2}{*}{0.06} \\
\hline Extended family & 22 & $92.22 \pm 8.38$ & & & $40.40 \pm 7.51$ & & \\
\hline \multicolumn{8}{|l|}{ No. of children in the family } \\
\hline 1 & 44 & $92.61 \pm 7.78$ & \multirow[t]{3}{*}{$1.58 *$} & \multirow[t]{3}{*}{0.66} & $44.36 \pm 7.90$ & \multirow[t]{3}{*}{$4.67^{*}$} & \multirow[t]{3}{*}{0.19} \\
\hline 2 & 39 & $92.87 \pm 8.68$ & & & $43.41 \pm 7.89$ & & \\
\hline 3 & 17 & $91.47 \pm 8.32$ & & & $42.23 \pm 6.29$ & & \\
\hline \multicolumn{8}{|l|}{ Age of getting married } \\
\hline $15-20$ & 48 & $93.50 \pm 8.09$ & \multirow[t]{3}{*}{$2.98^{*}$} & \multirow[t]{3}{*}{0.22} & $43.41 \pm 7.66$ & $0.46^{*}$ & 0.79 \\
\hline $21-25$ & 54 & $91.81 \pm 8.12$ & & & $42.66 \pm 7.72$ & & \\
\hline$>25$ & 11 & $88.18 \pm 11.09$ & & & $43.45 \pm 10.32$ & & \\
\hline Duration of marriage & & & & & & & \\
\hline $1-5$ years $^{\mathrm{a}}$ & 63 & $91.95 \pm 8.66$ & $3.07^{*}$ & 0.38 & $44.52 \pm 7.5$ & $10.48 *$ & 0.01 \\
\hline $6-10$ years $^{b}$ & 31 & $90.77 \pm 9.02$ & & & $39.67 \pm 8.08$ & & Diff. \\
\hline $11-15$ years $^{c}$ & 13 & $95.46 \pm 7.42$ & & & $45.23 \pm 8.17$ & & $a>b$ \\
\hline$>15$ years $^{d}$ & 6 & $94.667 \pm 3.93$ & & & $40.50 \pm 5.01$ & & $c>b$ \\
\hline Type of marriage (not arranged) & & & & & & & \\
\hline Companionate marriage (not arranged) & 64 & $94.31 \pm 7.59$ & $1,013.0 * *$ & 0.00 & $44.81 \pm 7.28$ & $1,135.0 * *$ & 0.01 \\
\hline Arranged marriage (traditional marriage) & 49 & $89.38 \pm 8.85$ & & & $40.77 \pm 8.17$ & & \\
\hline
\end{tabular}


TABLE 3 (Cont.) Comparison of maternal attachment and marital adjustment scores for mothers with descriptive

characteristics of the group.

Descriptive characteristics

Maternal Attachment Score

Marital Adjustment Score

\begin{tabular}{|c|c|c|c|c|c|c|c|}
\hline & $N=113$ & Mean $\pm S D$ & Test value & p-value & Mean $\pm S D$ & Test value & p-value \\
\hline \multicolumn{8}{|l|}{ Gender of the baby } \\
\hline Girl & 48 & $92.18 \pm 7.54$ & \multirow{2}{*}{$1,485.5^{* *}$} & \multirow{2}{*}{0.66} & $43.58 \pm 7.04$ & \multirow{2}{*}{$1,514.0 * *$} & \multirow{2}{*}{0.78} \\
\hline Boy & 65 & $92.16 \pm 9.18$ & & & $42.67 \pm 8.52$ & & \\
\hline \multicolumn{8}{|l|}{ Type of feeding for the baby } \\
\hline Breastfeeding exclusively & 58 & $94.86 \pm 6.36$ & \multirow[t]{3}{*}{$10.33^{*}$} & 0.00 & $43.53 \pm 8.42$ & \multirow[t]{3}{*}{$0.82 *$} & \multirow[t]{3}{*}{0.66} \\
\hline Breastfeeding + baby formula & 44 & $89.20 \pm 9.37$ & & Diff. & $42.54 \pm 7.60$ & & \\
\hline Breast milk by breast milking and baby formula & 11 & $89.90 \pm 10.61$ & & $1>2$ & $42.63 \pm 6.69$ & & \\
\hline \multicolumn{8}{|c|}{ Having a spouse who helps caring for the baby care } \\
\hline Yes & 80 & $93.16 \pm 8.42$ & \multirow{2}{*}{$962.5 * *$} & \multirow[t]{2}{*}{0.02} & $44.87 \pm 6.46$ & \multirow{2}{*}{$811.5^{* *}$} & \multirow[t]{2}{*}{0.001} \\
\hline No & 33 & $89.78 \pm 8.30$ & & & $38.66 \pm 9.35$ & & \\
\hline
\end{tabular}

$\mathrm{p}<0.05$ indicates statistical significance.

*KW: Kruskall Wallis.

**MV: Mann-Whitney U test.

TABLE 4 Comparison of maternal attachment and marital adjustment scores for mothers according to their pregnancy, natal and postnatal characteristics.

\begin{tabular}{|c|c|c|c|c|c|c|c|}
\hline & \multirow[b]{2}{*}{$N=113$} & \multicolumn{2}{|c|}{ Maternal Attachment Score } & \multicolumn{4}{|c|}{ Marriage Adjustment Score } \\
\hline & & Mean \pm SD & MWU value & p-value & Mean \pm SD & MWU value & p-value \\
\hline \multicolumn{8}{|l|}{ Type of conception } \\
\hline Normal & 109 & $91.95 \pm 8.55$ & \multirow[t]{2}{*}{121.50} & \multirow[t]{2}{*}{0.133} & $42.74 \pm 7.86$ & \multirow[t]{2}{*}{57.50} & \multirow[t]{2}{*}{0.01} \\
\hline Assisted reproductive techniques & 4 & $98.250 \pm 2.63$ & & & $51.75 \pm 2.50$ & & \\
\hline \multicolumn{8}{|l|}{ Planning of pregnancy } \\
\hline Planned & 92 & $92.88 \pm 7.57$ & \multirow[t]{2}{*}{808.50} & \multirow[t]{2}{*}{0.24} & $43.51 \pm 7.72$ & \multirow[t]{2}{*}{847.00} & \multirow[t]{2}{*}{0.37} \\
\hline Unplanned & 21 & $89.09 \pm 11.41$ & & & $41.09 \pm 8.59$ & & \\
\hline \multicolumn{8}{|c|}{ Experiencing problems during pregnancy } \\
\hline Yes & 21 & $93.42 \pm 7.38$ & \multirow[t]{2}{*}{884.50} & \multirow[t]{2}{*}{0.54} & $42.23 \pm 7.54$ & \multirow[t]{2}{*}{836.50} & \multirow[t]{2}{*}{0.33} \\
\hline No & 92 & $91.89 \pm 8.73$ & & & $43.25 \pm 8.01$ & & \\
\hline \multicolumn{8}{|c|}{ Getting regular checks during pregnancy } \\
\hline Yes & 87 & $93.35 \pm 7.80$ & \multirow[t]{2}{*}{750.00} & \multirow[t]{2}{*}{0.00} & $44.24 \pm 7.22$ & \multirow[t]{2}{*}{804.50} & \multirow[t]{2}{*}{0.02} \\
\hline No & 26 & $88.23 \pm 9.62$ & & & $39.11 \pm 8.91$ & & \\
\hline \multicolumn{8}{|l|}{ Attending pregnancy classes } \\
\hline Yes & 10 & $95.50 \pm 4.03$ & \multirow[t]{2}{*}{409.50} & \multirow[t]{2}{*}{0.28} & $49.20 \pm 5.71$ & \multirow[t]{2}{*}{240.00} & \multirow[t]{2}{*}{0.00} \\
\hline No & 103 & $91.85 \pm 8.75$ & & & $42.46 \pm 7.85$ & & \\
\hline \multicolumn{8}{|l|}{ Type of delivery } \\
\hline Normal & 59 & $90.94 \pm 8.86$ & \multirow[t]{2}{*}{$1,330.50$} & \multirow[t]{2}{*}{0.13} & $42.83 \pm 7.37$ & \multirow[t]{2}{*}{$1,549.50$} & 0.80 \\
\hline C-section & 54 & $93.51 \pm 7.93$ & & & $43.31 \pm 8.51$ & & \\
\hline Experiencing problems during del & very & & & & & & \\
\hline Yes & 13 & $94.46 \pm 7.17$ & 537.50 & 0.31 & $42.07 \pm 9.6$ & 571.50 & 0.47 \\
\hline No & 100 & $91.88 \pm 8.63$ & & & $43.19 \pm 7.70$ & & \\
\hline Baby staying in hospital after birth & & & & & & & \\
\hline Yes & 39 & $91.308 \pm 8.38$ & $1,279.00$ & 0.32 & $41.61 \pm 8.65$ & $1,190.00$ & 0.12 \\
\hline No & 74 & $92.63 \pm 8.57$ & & & $43.82 \pm 7.43$ & & \\
\hline
\end{tabular}


TABLE 5 Correlation between level of maternal attachment and marital adjustment levels for mothers.

Maternal attachment

Marital adjustment

$\begin{array}{ll}\mathrm{r} & 0.38 \\ \mathrm{P} & 0.00\end{array}$

\section{TABLE 6 The impact of marital adjustment on maternal attachment.}

\begin{tabular}{llllllll} 
Dependent variable & Independent variable & $\mathbf{B}$ & $\mathbf{t}$ & $\mathbf{P}$ & $\mathbf{F}$ & Model (p) & $\mathbf{R}^{2}$ \\
\hline \multirow{2}{*}{ Maternal attachment } & Constant & 71.995 & 17.938 & 0.000 & 26.131 & 0.000 & 0.183 \\
\cline { 2 - 7 } & Marital adjustment & 0.469 & 5.112 & 0.000 & & & \\
\hline
\end{tabular}

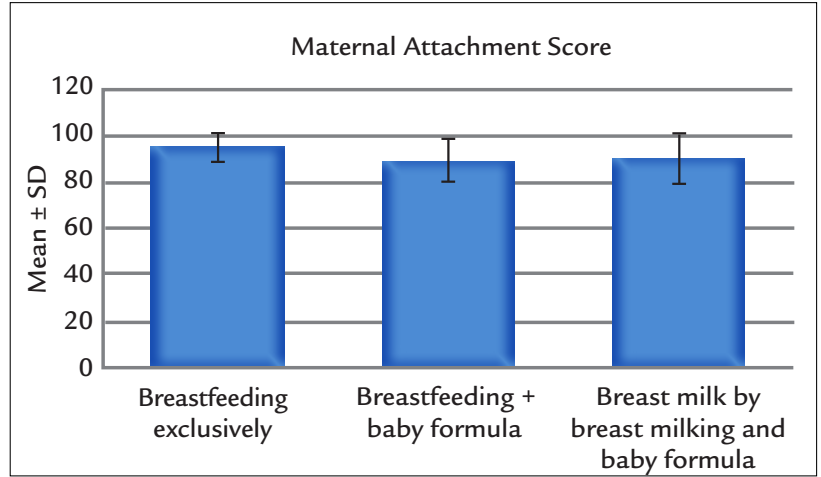

FIGURE 1 The relationship between type of feeding for the baby and maternal attachment.

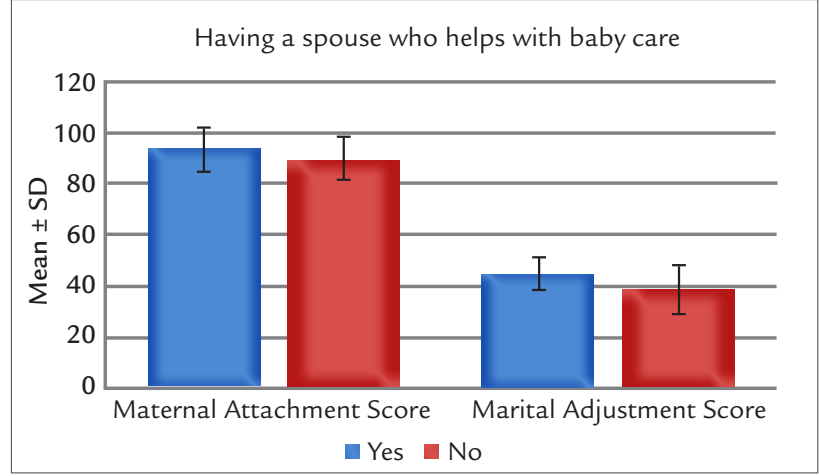

FIGURE 2 The relationship between having spouse who helps caring for the baby and maternal attachment and marital adjustment.

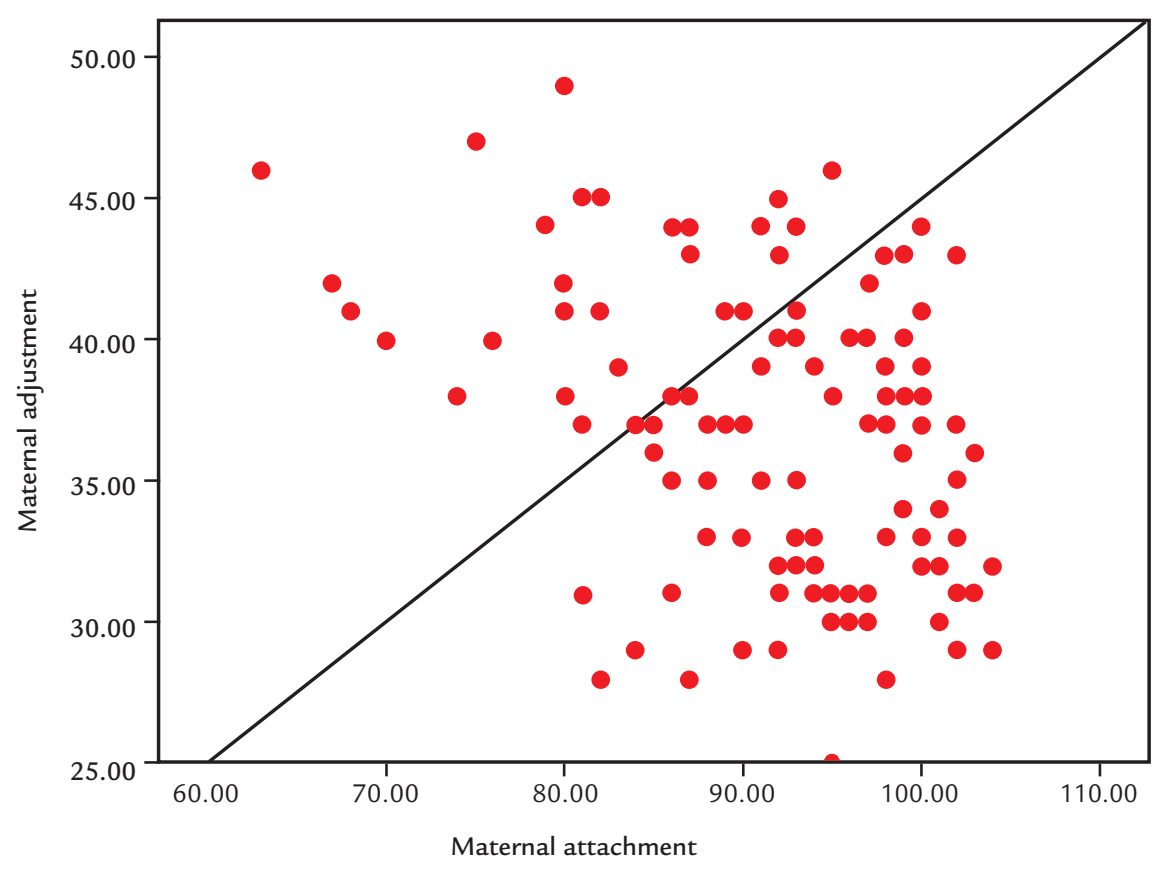

FIGURE 3 The relationship between maternal attachment and marital adjustment. 
marriage was 6-10 years (Table 3). Duration of marriage influences marital adjustment. The literature shows that the marital adjustment is lower during the first years of marriage; however, as the duration of marriage increases and children leave home, it increases. ${ }^{24}$ One study found that the marital adjustment is higher for those who are married for 6-10 years. ${ }^{23}$ According to a study by Yalçın examining the relationship between sociodemographic characteristics of women and their marital adjustment, as duration of marriage increased, women's tendency to evaluate their marriage as "good" decreased. Additionally, conflicts decreased as they were discussed, violence and fights increased, and the tendency of $50 \%$ of the women was to remain silent. ${ }^{24}$ In a research examining the marital adjustment status of graduate students, there was no statistically significant relationship between duration of marriage and their marital adjustment. ${ }^{25}$

We also observed that the marital adjustment scores for mothers who were working were higher compared to those who were not working; and the highest marital adjustment scores belonged to mothers who were university graduates (Table 3). As level of education increases, the rate of working for individuals also increases. For marriage and family life, working status of spouses positively contributes to the marriage and the family. ${ }^{3}$ A study also found that the level of marital adjustment was higher for those having undergraduate and above degrees, civil servants and having more income than expenses. ${ }^{23}$ These findings suggest that high level of education and income increases economical, social and cultural prosperity of individuals; and the adjustment in marriages increases in such conditions. Education is a variable related to marital adjustment. As level of education increases, couples may express their emotions and ideas to each other more comfortably and accurately and understand their spouses by experiencing empathy. Moreover, as level of education increases, both spouses may try to resolve conflicts and disagreements by respecting opinions and ideas of each other. ${ }^{24}$

The level of maternal attachment and marital adjustment for mothers is affected by numerous factors related to pregnancy, natal and postnatal period. In our study, there was no statistically significant difference ( $p>0.05)$ between maternal attachment and type of conception, planning of pregnancy, experiencing problems during pregnancy, attending pregnancy classes, delivery method and experiencing problems during giving birth. We observed that the maternal attachment scores for mothers who undergone regular checks were statistically significantly higher compared to those who did not $(\mathrm{p}<0.05)$
(Table 4). Similarly, in the study conducted by Öztürk and Saruhan, it was determined that maternal attachment scores were higher in the mothers who received prenatal care. ${ }^{18}$ Based on these findings, we can say that having regular checks before giving birth reduces problems that may be experienced in the pre and postnatal periods, in addition to the fact that mother-baby attachment is positively effected in this health period. Also, mothers who received information about birth and postpartum care during pregnancy demonstrate better attachment to their babies after birth. ${ }^{26}$ This positively affects motherbaby attachment after giving birth.

There was a statistically significant relationship between the perception of spouses towards their marriage or their level of satisfaction with their relationship and being sensitive parents. The consistency in the relationship between spouses is also important for the baby to understand relationship connections. Tension between parents causes negative affectivity in mother-father-baby relationships. ${ }^{27}$ Moreover, lack of adjustment between spouses may negatively affect the parents' roles as mother and father. ${ }^{7}$ Parents demonstrate more positive attitudes towards their children in a coherent and happy marriage life with well-developed communication. ${ }^{17}$ In our study, we found a statistically significant, weak and positive relationship between marital adjustment and maternal affection $(p<0.05)$. The regression analysis performed to identify the relationship between marital adjustment and maternal attachment proved to be statistically significant $(\mathrm{F}=26.131$; $\mathrm{p}<0.05)$. We observed that the correlation between the maternal attachment and marital adjustment variables, which is a determinant of maternal attachment level (explanatory power $)$, is weak $\left(\mathrm{R}^{2}=0.183\right)$. The level of marital adjustment for mothers increases their level of maternal attachment $(B=0.469)$ (Table 6) and its weight on maternal attachment is $18.3 \%$ (Table 5). In their research, Alan and $\mathrm{Ege}^{17}$ found a statistically significant correlation between average of MAI scores for mothers and their overall communication with their spouses. In other words, the MAI scores for mothers who stated that they had good communication with their spouses were higher. A study by Akkocaa $^{22}$ investigating the mother-baby attachment after birth revealed that marital maladjustment negatively affects mother-baby attachment. These results support the findings of our research. In light of the research findings and information in the literature, we can say that the expected adjustment between spouses occurs in a happy marriage, this adjustment makes parents develop appropriate and desired relations with their children and strengthens the attachment between mother and baby. 


\section{Conclusion}

We found that the maternal attachment level for mothers of babies aged 1-4 months who were treated in hospital was high. Their level of marital adjustment was liminal, and there was a weak and positive correlation between marital adjustment and maternal attachment. As the level of marital adjustment increased, the level of maternal attachment increased as well. According to our findings, there are many factors affecting levels of maternal attachment and marital adjustment for mothers. We found that the level of maternal attachment was higher for mothers who had a high school or university degree, got married by companionship, breastfed exclusively, got regular checks during pregnancy, and whose spouses helped care for the baby. In terms of marital adjustment, the marital adjustment scores were higher for mothers who were working, had a university degree, were married for $1-5$ years and 10-15 years, got married by companionship, became pregnant with the aid of reproductive techniques, got regular checks during pregnancy and attended pregnancy classes, and whose spouses helped care for the baby. Still in accordance with our findings, in order to support mother-baby attachment and marital adjustment, the importance of improving the level of education, getting married by companionship, benefits of getting regular checks and pregnancy classes during pregnancy, breastfeeding exclusively during the first 6 months after birth, and having a spouse that helps care for the baby should be explained. In this context, nurses and other healthcare employees should support mothers since before giving birth by providing counseling to spouses and training. Spouses should be included in the process of mother-baby attachment, and the importance of marital adjustment for both mother and baby should be emphasized for couples during pregnancy observations and classes. It should be explained that there is a relationship between marital adjustment and maternal attachment; and marital adjustment increases maternal attachment.

\section{References}

1. Kışlak-Tutarel Ş, Göztepe I. The relationship between emotional expression, empathy, depression and marital adjustment. Ankara Üniversitesi Sosyal Bilimler Enstitüsü Dergisi. 2012;3(2):27-46.

2. Saxton L. Marriage: the nature of marriage, the individual, marriage, and the family. $5^{\text {a }}$ ed. Belmont: Wadsworth Publishing Company Belmont; 1982.
3. Çelik M, Tümkaya S. The relationship between marital adjustment and life satisfaction of instructors and work variables. Ahi Evran Üniversitesi Kırșehir Eğitim Fakültesi Dergisi (KEFAD) 2012;13(1):223-38.

4. Çelik M. Study on developing marital satisfaction scale [unpublished $\mathrm{PhD}$ thesis]. Adana: Çukurova University Social Sciences Institute Department of Educational Sciences; 2006.

5. Ekşi $\mathrm{H}$, Kahraman $Z$. The effect of a marriage and family life training program on marital adjustment of married women and family system. M. ̈̈. Atatürk Eğitim Fakültesi Eğitim Bilimleri Dergisi. 2012;36:129-45.

6. Yeşiltepe SS. An evaluation of marital adjustment of teachers from the perspective of psychological well being and some variables. [unpublished master thesis]. Adana: Çukurova University Social Sciences Institute Department of Educational Sciences; 2011.

7. Özbey S. the evaluation of the relationship between marital adjustment of parents and their perceived social support and problematic behaviors of six-year-old children. Kastamonu Eğitim Dergisi 2012;20(1):43-62.

8. Bandura A. Social learning theory. New York City: General Learning Press; 1977. Available from: http://www.esludwig.com/uploads/2/6/1/0/26105457/ bandura_sociallearningtheory.pdf.

9. Henderson AD, Sayger TV, Horne AM. Mothers and sons: a look at the relationship between child behavior problems, marital satisfaction, maternal depression, and family cohesion. Family J. 2003;11(1):33-41.

10. Güleşen A, Yıldız D. Review of mother-baby attachment in early postpartum period through evidence-based applications. TAF Preventive Medicine Bulletin 2013;12(2):177-82.

11. Müller ME. A questionnaire to measure mother-to-infant attachment. J Nurs Meas. 1994;2(2):129-41.

12. Kavlak $O$, Sirin A. The Turkish version of maternal attachment inventory. J Human Sciences. 2009;6(1):188-202.

13. Bretherton I. The origins of attachment theory: John Bowlby and Mary Ainsworth. Dev Psychol. 1992;28(5):759-75.

14. Mercer RT, Ferketich SL. Maternal-infant attachment of experienced and inexperienced mothers during infancy. Nurs Res. 1994;43(6):344-51.

15. Locke HJ, Wallace KM. Short marital-adjustment and prediction tests: their reliability and validity. Marriage and Family Living. 1959;21:251-5.

16. Kışlak-Tutarel Ş. Validity and reliability study on marital adjustment scale (MAS). 3P Psikiyatri Psikoloji Psikofarmakoloji Dergisi. 1999;7(1):54-6.

17. Alan H, Ege E. The influence of social support on maternal-infant attachment in Turkish society. Anadolu Hemşirelik ve Sağlık Bilimleri Dergisi. 2013;16(4):234-40.

18. Öztürk R, Saruhan S. Review of the relationship between depression and maternal attachment for mothers who have 1-4-month-old premature babies treated in hospital. HEMAR-G 2013;1:32-47.

19. Shin H, Kim YH. Maternal Attachment Inventory: psychometric evaluation of the Korean version. J Adv Nurs. 2007;59(3):299-307.

20. Mutlu C, Yorbık Ö, Tanju İA, Çelikel F, Sezer RG. The relationship between before, during and after birth factors and maternal attachment. Psikiyatri Dergisi 2015;16(6):442-50.

21. Himani BK, Kumar P. Effect of initiation of breast-feeding within one hour of the delivery on 'maternal-infant bonding'. Nursing Midwifery Res J. 2011;7(3):99-109.

22. Akkoca Y. Factors affecting mother-baby attachment after birth [unpublished specialty thesis]. Ankara: Gazi University Faculty of Medicine Department of Psychiatry; 2009.

23. Ende İnce $Z$, Güdücü Tüfekçi F. Identifying marital adjustment and life satisfaction of parents with disabled child and affecting factors. Gümüşhane Üniversitesi Sağlık Bilimleri Dergisi. 2015;4(1):102-22.

24. Yalçın $H$. The relationship between marital adjustment and sociodemographic charactersitics. Ĕ̆itim ve Öğretim Araştırmaları Dergisi. 2014;3(1):250-61.

25. Fişıloğlu H. Marital adjustment of graduate students. Psikoloji Dergisi 1992;7(28):16-23.

26. Köse D, Çınar N, Altınkaynak S. Marital adjustment period of the new born to mother and father. STED. 2013;22(6):239-45.

27. Soysal AŞ, Bodur Ş, İşeri E, Şenol S. An overview of the attavhment process during infantiliy. Klinik Psikiyatri. 2005;8(2):88-99. 